\title{
Let's change the field
}

\author{
Richard Ferber ${ }^{1,2 *}$ \\ 1 Children's Hospital Boston, Boston, MA, USA \\ 2 Harvard University, Cambridge, MA, USA \\ *Correspondence: richard.ferber@childrens.harvard.edu
}

We need to change how we think about sleep function, mechanism, control, dysfunction, and treatment. That is the challenge that is put forward in this journal.

The challenge applies to the fields of sleep research and clinical sleep medicine at all levels and disciplines. This journal is to be eclectic in scope and ambitious in goal, from basic to applied science, from microscope to macroscopic function, from nucleic acid to neuronal systems, from fetus to adult, and from primitive organisms to the highly evolved.

The fields of sleep research and circadian biology have existed for many years; the field of modern clinical sleep medicine only 40 years or so. But how long did we know about sleep before we knew about REM and NREM (Aserinsky and Kleitman, 1953)? How long did we know that most of us slept at night before we knew about the suprachiasmatic nucleus, the circadian clock, and their mode of control (Rusak and Zucker, 1979; Rosenwasser, 1988)? How long did we know about narcolepsy before we knew about the $\mathrm{DQB} 1^{\star} 0602$ genetic locus and about the orexin/hypocretin neurotransmitter system (Mignot et al., 1997; Nishino et al., 2000; Taheri et al., 2002)? How much did we know about neuroanatomy and neurophysiology before we started to unravel the interplay of central systems controlling sleep? How long did we know about obstructive sleep apnea before we recognized it as a common disorder with a simple effective treatment (Sullivan et al., 1981)? How long did we ascribe a psychodynamic dream interpretation to sleepwalking and sleep terrors before we learned to think of them as NREM disorders of arousal (Broughton, 1968)? How long did we treat narcoleptic patients as "lazy" before we recognized narcolepsy's genetic and neurophysiologic bases? How long did we unquestioningly treat all insomniacs with barbiturates before we learned about sleep hygiene, sleep phases, and restless legs? How long did we ignore the impact of sleep deprivation on daily function, learning, and mood and why are so many still doing just that? And how many aspects of sleep are we still thinking about incorrectly because we continue to accept the common wisdom without questioning it, and because we have failed to widen our horizons sufficiently? And how many patients are still being treated inadequately because of approaches that continue to be based on tradition rather than science?

Scientific studies that lead to significant changes in the field are the most important, and the fields of sleep research, circadian biology, and sleep disorders medicine are ripe for such changes. Not all studies can be as suddenly game changing as the discovery of REM sleep, but they do not need to be to change the way we think, the way we direct future research, and the way we treat our patients. From careful thought comes new speculation, then postulation, and then hypothesis generation. But these are only of value if these hypotheses are then tested in well-designed studies.

The challenge is simple. Do not just accept what has been taught without careful questioning. Do not just design studies that can be done, but design studies that need to be done. Do not just conduct these studies in the easiest ways, but do so in the ways most likely to assure useful, reliable, and confirmable outcomes.

Let us change the field.

\section{REFERENCES}

Aserinsky, E., and Kleitman, N. (1953). Regularly occurring periods of eye motility, and concomitant phenomena, during sleep. Science 118, 273-274.

Broughton, R. (1968). Sleep disorders: disorders of arousal? Science 159, 1070-1078.

Mignot, E., Hayduk, R., Black, J., Grumet, F. C., and Guilleminault, C. (1997). HLA DQB1 ${ }^{\star} 0602$ is associated with cataplexy in 509 narcoleptic patients. Sleep 20, 1012-1020.

Nishino, S., Ripley, B., Overeem, S., Lammers, G. J., and Mignot, E. (2000). Hypocretin (orexin) deficiency in human narcolepsy. Lancet 355, 39-40.

Rosenwasser, A. M. (1988). Behavioral neurobiology of circadian pacemakers: a comparative perspective. Prog. Psychobiol. Physiol. Psychol. 13, 155-226.

Rusak, B., and Zucker, I. (1979). Neural regulation of circadian rhythms. Physiol. Rev. 59, 449-526.

Sullivan, C. E., Issa, F. G., Berthon-Jones, M., and Eves, L. (1981). Reversal of obstructive sleep apnea by continuous positive airway pressure applied through the nares. Lancet 1, 862-865.

Taheri, S., Zeitzer, J. M., and Mignot, E. (2002). The role of hypocretins (orexins) in sleep regulation and narcolepsy. Annu. Rev. Neurosci. 25, 283-313.

Received: 01 May 2010; accepted: 03 May 2010; published online: 28 May 2010.

Citation: Ferber R (2010) Let's change the field. Front. Psychiatry 1:13. doi: 10.3389/fpsyt.2010.00013

This article was submitted to Frontiers in Sleep Disorders, a specialty of Frontiers in Psychiatry.

Copyright (c) 2010 Ferber. This is an open-access article subject to an exclusive license agreement between the authors and the Frontiers Research Foundation, which permits unrestricted use, distribution, and reproduction in any medium, provided the original authors and source are credited. 